\title{
ENTRE REVOLUCIONES E INTELECTUALES: TENSIÓN, RUPTURA Y REENCUENTRO DE MÉXICO Y PERÚ (1924-1933)'
}

\author{
Between revolutions and intellectuals: tension, rupture \\ and reunion of Mexico and Peru (1924-1933)
}

\author{
Fabián Herrera León \\ Instituto de Investigaciones Históricas, México
}

\begin{abstract}
Resumen: La relación histórica entre México y Perú tuvo uno de los momentos de mayor tensión y desvanecimiento durante la primera mitad de la década de 1930, como consecuencia de sus respectivas revoluciones y del trato especial que México concedió a la Alianza Popular Revolucionaria Americana en detrimento de la relación oficial entre Estados. Este breve episodio, determinado en gran medida por el peso extraordinario de la interacción cultural representada por intelectuales revolucionarios, no pasó desapercibida internacionalmente por sus posibles implicaciones, tanto en el ámbito regional latinoamericano, como en el multilateral ginebrino de la Sociedad de Naciones, donde se intentaría poner fin al conflicto amazónico entre Perú y Colombia por el puerto amazónico de Leticia.
\end{abstract}

Palabras clave: relaciones México-Perú, Víctor Raúl Haya de la Torre, José Vasconcelos, conflicto de Leticia, Sociedad de Naciones.

\begin{abstract}
The historical relationship between Mexico and Peru suffered one of the moments of greatest tension and fading during the first half of the 1930s as a result of their respective revolutions and the special treatment that Mexico granted to the Alianza Popular Revolucionaria Americana in detriment to the official relationship between states. This brief episode, largely determined by the extraordinary weight of the cultural interaction represented by revolutionary intellectuals, did not go unnoticed internationally due to its possible implications both in the Latin American regional sphere and in the multilateral Geneva sphere of the League of Nations, where an attempt would be made to put an end to the Amazonian conflict between Peru and Colombia through the Amazonian port of Leticia.
\end{abstract}

Keywords: Mexico-Peru relations, Víctor Raúl Haya de la Torre, José Vasconcelos, Leticia conflict, League of Nations.

1. Agradezco a los estudiosos peruanos Mario Miguel Meza Bazán y Pablo Sandoval los acertados consejos de investigación que compartieron conmigo durante la realización de este artículo. 


\section{A manera de introducción. Una relación liviana y sin sobresaltos}

Apenas propiciada por la independencia, la relación histórica entre México y Perú parece levitar sobre una imposible dimensión geográfica que solo la integración futura del Pacífico podría sujetar y hacer aterrizar realmente. Al paso de dos siglos, la relación ha ganado profundidad en su natural dimensión americana y de desarrollo periférico, pero apenas pesa, lo que evidencia aún la distancia insalvable entre el norte y el sur, así como las orientaciones e intereses distintos no obstante los imprescindibles supuestos retóricos y diplomáticos que hablan de relevancia. ${ }^{2}$ Antes, reinos americanos, y ahora, naciones latinoamericanas, Perú y México se reconocen desde la lejanía, voltean a verse casi accidentalmente, pero de modo que contribuyen a una relación llevadera y fraternal. ¿Podría ser de otro modo? Eventualmente sí, en disonancia con los temas de enorgullecimiento mutuo: el remoto aunque limitado contacto y tránsito humano y mercantil (primordialmente contrabando) a partir de la colonia; la supervivencia como naciones independientes con apoyo en amenazantes - aunque en la práctica imposibles - tratados de defensa común, cuya excepcional materialización por parte de Perú durante la intervención francesa representa, sin duda, el momento más memorable y dramático de esta historia; ${ }^{3}$ la fundación, en 1942, del Instituto Cultural Peruano-Mexicano y la de la Casa de México en Lima dos años después; y la coincidencia política y retórica entre los gobiernos de Luis Echeverría Álvarez y Juan Velasco Alvarado, comparable a la intención de los presidentes Carlos Salinas y Alberto Fujimori de buscar un acuerdo de libre comercio.

Los malos recuerdos, aunque profundos, son menos y no suelen encontrar lugar en la memoria de una relación bilateral que se pretende sana y respetuosa. Entre ellos, estarían el rechazo sin explicaciones de la propuesta peruana de binacionalidad, lo mismo para los ciudadanos de Perú como para los de México (1822); el desencuentro con la Confederación Perú-Boliviana y la consecuente ruptura de relaciones entre 1839 y 1841, comparable con el distanciamiento de la revolución mexicana con el llamado Oncenio de Augusto B. Leguía y el gobierno inmediato del líder golpista Luis Miguel Sánchez Cerro.

Este último desencuentro, de casi quince años, enmarca este artículo, dedicado a la incidencia extraordinaria de los intelectuales en el curso de la relación, aunque no, como podría suponerse, desde aquellos cuerpos diplomáticos lati-

2. La relación entre los que alguna vez fueron los principales virreinatos españoles ha merecido la atención de varios especialistas y sus obras constituyen el principal referente historiográfico: Ruiz Guerra (2007); Palacios (2011) y Andújar de Jesús (2006). Sobre el particular pudo escribir brevemente Reyes (2010). También existen útiles estudios de compendio y registro: Guzmán y Raz Guzmán (1925) y Montalvo (1981).

3. Dramático porque sus representantes, encabezados por el poeta Manuel Nicolás Corpancho, no solo apoyaron la causa republicana juarista, motivo por el que fueron expulsados por la regencia del Segundo Imperio, sino que además perdieron la vida tras embarcarse en aguas del golfo de México. Un episodio digno de mención y memoria que apenas se hace presente en la relación bilateral presente. Al respecto, véanse: Estrada (1923) y Real de Azúa (1978). 
noamericanos poco profesionales que entonces solían incluirlos. También podremos advertir cuán relevante, en un sentido negativo, pudo tornarse una relación desapasionada y flotante, de manera que desencadenó un problema internacional capaz de complicar agendas diplomático-políticas superiores en el plano multilateral. Esto supone relativizar las diferencias y sus causas, así se trate de figuras descollantes y poco predecibles, como lo fueron las de José Vasconcelos y Víctor Raúl Haya de la Torre, o de afinidades ideológicas y espirituales, como las que identificarían a la revolución mexicana con la Alianza Popular Revolucionaria Americana (APRA). Lo que en última instancia podrá apreciarse, gracias a esta inusual problematización, es cómo el interés nacional encuentra finalmente su lugar como factor predominante en un proceso de regeneración y reconducción de relaciones entre Estados. En el caso de México y Perú habrá de apreciarse, a manera de hipótesis, la incidencia determinante de un plano supranacional en torno a la Sociedad de Naciones (en adelante, SDN) y de las medidas concebidas en su ámbito multilateral para facilitar los acuerdos de pacificación de Leticia que dirigiría el primero de estos Estados y que involucraría al segundo.

Esta claridad de intereses estatales cambiaría la perspectiva desde la que podrían mirarse los problemas surgidos en el curso de una relación descuidada por México y Perú en esos años, que puestos en su justa dimensión no podían sino, sencillamente, ser desplazados en aras de mayores beneficios comunes.

El estudio de este problema de historia internacional y de actores transnacionales informales u oficiosos pretende una contribución original a la comprensión tradicional de la relación bilateral y sus imprevistos altibajos, aprovechando una perspectiva histórica suficiente de casi cien años y la disposición y fácil acceso a fuentes de archivo diplomático, así como a significativas aportaciones historiográficas en el ámbito de la historia intelectual americana y de sus relaciones internacionales para los planos multilateral y oficioso.

\section{Intelectuales en escena: revolucionarios espirituales y Haya de la Torre en México}

Nuestro tiempo, en definitiva, no es más el de los intelectuales occidentales propios del siglo xx: presentes en escena en cuanto que actores notables y reputados, capaces de iluminar causas políticas y sociales, y de oponerse a injusticias humanas diversas; figuras perversamente procuradas en razón de su halo de legitimación y credibilidad por un sinnúmero de gobernantes temerosos, impopulares y/o autoritarios que protagonizaron ese pasado que nos es aún tan próximo y propio. Este protagonismo del intelectual consagrado se ha desdibujado entre aquel siglo y el curso que sigue, el nuestro, tal como pudo advertir Tony Judt (2008); este autor abordó en el libro el papel de las ideas y la responsabilidad de los intelectuales a lo largo de ese convulso siglo. Y ciertas ideas y planteamientos en él inspiran el presente artículo, pensado para una realidad americana distinta en la que también son significativas ciertas figuras con una dimensión tanto nacional como internacional: 


\begin{abstract}
En los estados en los que la oposición y la crítica eran (son) reprimidas, los intelectuales asumieron individualmente el papel de portavoces de los intereses públicos y de los ciudadanos, contra la autoridad y el Estado. Pero incluso en las sociedades abiertas el intelectual del siglo xx adquirió cierto estatus público y se benefició no solo del derecho a la libre expresión, sino también de la alfabetización casi universal de las sociedades avanzadas, que le garantizaba su audiencia (Judt, 2008: 24).
\end{abstract}

El siglo xx, como lo estimaría George Orwell en el curso de su primera mitad, decantaría a este tipo de intelectual predominantemente hacia la «izquierda», postura desde la que condenaría y rechazaría el orden existente (Orwell, 2009 [1940]: 119). A contraluz de un hispanismo tradicional, el antiimperialismo sería la expresión más clara de esta insatisfacción intelectual en América Latina y bien podría representar su propio abandono del arte por el arte. Tal como lo refiere Carlos Altamirano en las primeras páginas de Historia de los intelectuales en América Latina, Alfonso Reyes reflexionaría profundamente sobre el arribo tardío de América Latina al «banquete de la civilización» occidental (Altamirano, 2008: 10), un sentimiento que compartiría la élite intelectual latinoamericana en la búsqueda de su validación (Dumont, 2018: 36-40; Pita González, 2019) no obstante la autenticidad y circulación dinámica de sus ideas en el subcontinente. El antiimperialismo representaría asimismo una identificación común ante el pluralismo ideológico y político de estos actores, creadores o facilitadores de un pensamiento propicio para el cambio o la contención nacional y continental. Este mosaico antiimperialista ubicaría en su centro la figura del antiyanquismo e hilaría una extensa red intelectual integrada por diversos miembros de la «elite pensante americana» (Pita González, 2019: 49; 2016). Una «inteligencia americana» consistente, en palabras de Carlos Altamirano, de «hombres de letras aplicados a la legitimación del orden e intelectuales críticos del poder, vanguardias artísticas y vanguardias políticas surgidas de las aulas universitarias» (Altamirano, 2008, I: 10). El peruano Víctor Raúl Haya de la Torre y el mexicano José Vasconcelos se contarían entre los últimos. La palabra inconfundible de este último habría de ser escuchada por los estudiantes de San Marcos en 1916:

No somos simplemente una América inconclusa, una América segunda de nuestra vecina del norte. La sajona fue una América libre y abierta para todos los blancos, hecha con los mismos hijos del continente antiguo, mientras que la nuestra es patria y obra de mestizos, de dos o tres razas por la sangre y de todas las culturas por el espíritu (Tomado de Fell, 2021: 797).

En general, la lectura negativa de las políticas y acciones estadounidenses en el continente contrastaría con la apreciación del universalismo europeo (Pita González, 2014: 83) y de las principales manifestaciones políticas de la primera posguerra, tales como la puesta en marcha del multilateralismo con eje en la SDN, la aparición de gobiernos de frente popular y, por supuesto, el curso de las revoluciones soviética, fascista y nacionalsocialista. Pero sería la revolución mexicana el fenómeno de mayores afectos entre la intelectualidad latinoamericana, por sentirla tan cercana como posible en cuanto que testigos de «un laboratorio donde realizar posibles proyectos nacionales y materializar soñadas 
utopías de regeneración y unión continental» (Yankelevich, 2003: 14). ${ }^{4}$ La revolución en México se consolidaría al paso de dos décadas: la primera, de intermitente lucha armada, y la siguiente, de claro distanciamiento respecto del modelo económico y social de corte liberal que se había consolidado durante el porfiriato, dando lugar a una relevante reforma agraria, a la incorporación de un movimiento obrero fuerte y a una reivindicación popular y educativa generales. La revolución suscitó expectativas en unos y preocupaciones en otros:

\begin{abstract}
Como no podía dejar de ser los movimientos revolucionarios de la década de 1910 provocaron una revolución en las relaciones de México con los países de América del Sur, la mayor parte de ellos gobernados por coaliciones conservadoras, casi todas seguidoras y aliadas de la Iglesia Católica - uno de los enemigos favoritos de los liderazgos revolucionarios. La añeja imagen del México «bronco» y violento, desordenado y anárquico, construida en el imaginario sudamericano a lo largo del siglo XIX, resurgió como un fénix terrible en medio de las humaredas de las primeras batallas. Asustó a los círculos gobernantes sudamericanos y entusiasmó a sus contados oponentes - pequeños partidos socialistas, precarias mutualidades anarco-sindicalistas, asociaciones estudiantiles - y llevó al Departamento de Estado de Washington a inundar las capitales sudamericanas con panfletos y filmes de propaganda contra-revolucionaria durante los años centrales de la década (Palacios, 2017: 83).
\end{abstract}

El perfil nacionalista de la revolución y su filiación ideológica - articulada, según el análisis de Francisco Zapata, como nacionalismo revolucionario - refiere a una defensa de nuevos principios constitucionales nacionalistas, antioligárquicos y antiimperialistas, favorables a la unidad de los distintos grupos sociales de una nación y a la reivindicación de los sectores populares: «Por ello es que en el nacionalismo revolucionario no se puede encontrar el enfrentamiento de clases como motor del desarrollo social» (Zapata, 2001: 16-17); su alianza es el elemento motor y la esencia que consideraría el peruano Víctor Raúl Haya de la Torre al sentar la base política de la Alianza Popular Revolucionaria Americana (APRA) en el curso de su exilio, "entre Londres y París, congregando estudiantes y desterrados" (Melgar Bao, 2018: 24). Su discurso priorizaría el combate continental al imperialismo (Iglesias, 2014: 6). El ámbito inicial de creación de la APRA fue la Universidad Nacional en México, plataforma política continental para el principal responsable del asilo de Haya de la Torre en México: José Vasconcelos (Vasconcelos, 1979 [1938]: 93-94, 180, 200-201). El medio intelectual latinoamericano reconocería al maestro como uno de los grandes impulsores de la revolución cultural y educativa mexicana, además de un protector de jóvenes transterrados que más tarde intentarían cambios políticos trascendentales en sus respectivos países (Pita González, 2014: 136). Su imagen compartiría ese atractivo continental propio de las figuras producto de la revolución, amalgama del ser político a la vez experto y fundador de instituciones y pensamiento para el futuro, aderezada por la ambición de un movimiento educativo propio (Moraga Valle, 2014: 168). Estos constructores de puentes, quizá más sólidos que los

4. Un elaborado contexto a nuestro estudio es el trabajo de Rivera Mir (2018) centrado en los militantes radicales de la izquierda latinoamericana. 
tradicionales, procurarían problemáticas comunes, como muy bien podría ejemplificar la del indio entre México y Perú, pensada y planteada por Manuel Gamio, Alfonso Caso, Miguel Othón de Mendizábal, Moisés Sáenz, el propio Vasconcelos, Manuel González Prada, Luis E. Valcárcel y, también, Haya de la Torre y José Carlos Mariátegui. ${ }^{5}$

Joven ateneísta por la apertura cultural y caudillo revolucionario de la misma causa (Krauze, 1996 [1976]: 46-52), José Vasconcelos fue el más importante intelectual político latinoamericano de la primera mitad del siglo xx, capaz de descomponer la escena regional con la expresión natural de un juicio moral sobre el autoritarismo. Esta fuerza sonora podía trastocar la aparente calma de regímenes de apariencia rígida, o bien inacabada, como el surgido en México con la revolución. Tales condiciones son propicias para la configuración de este tipo de episodios internacionales extraordinarios en torno a una sola persona al margen de una política oficial, pero sin duda representativa de una opinión - en este caso estudiantil - amplia. Una polémica internacional de esta naturaleza puede hacer que el Estado y sus instituciones parezcan meras agencias de trámite o apagafuegos. Tal sería, por decirlo de una manera general, la razón y curso de las críticas internacionales que dirigió Vasconcelos al gobierno venezolano de Juan Vicente Gómez en octubre de 1920 y que canceló la relación bilateral por una década, así como las que dedicó al gobierno del referido Augusto Bernardino Leguía en Perú en el curso de su oncenio en el poder (1919-1930). ${ }^{6}$ Vinculado a organizaciones estudiantiles sudamericanas que lo reconocían como su maestro, el entonces rector mexicano dirigía la cruzada educativa continental más importante después de la de Córdoba, que reconocía como una creciente «revolución estudiantil» (Fell, 2021: 800, 890) muy próxima al reformismo universitario de San Marcos y La Habana (Marsiske, 2003). Como muestra clara de su inclinación ante el vigoroso movimiento universitario de estudiantes en torno a la revolución mexicana (Robinet, 2015), Vasconcelos no había dudado en referirse a Gómez como un tirano (Fell, 2021: 801-803, 808-809; Moraga Valle, 2014: 168-171) y había empleado descalificaciones gráficas que en ningún modo sancionó el gobierno de Álvaro Obregón, ${ }^{7}$ con lo que dio pie a que Gómez ordenara la interceptación de un barco mexicano en 1923 y a que se produjera un inevitable rompimiento. ${ }^{8}$ En efecto, la crisis

5. Sobre el amplio espectro de influencia mexicana en el tema del indigenismo como saber del Estado posrevolucionario y su contacto con el pensamiento académico y antropológico peruano, véase: Sandoval López (2020: 32-88).

6. Había gobernado previamente entre 1908 y 1912.

7. Que si bien era favorable a distinguirse revolucionariamente en su complicada situación con Estados Unidos por el reconocimiento a su gobierno, tampoco deseaba verse relacionado con la Comintern u otras manifestaciones internacionales próximas a la revolución soviética (Jeifets y Jeifets, 2013).

8. En un discurso público, el 12 de octubre de 1920, el rector Vasconcelos se había referido a Juan Vicente Gómez como «el último de los tiranos de la América española, el más monstruoso; el más repugnante y el más despreciable de todos los déspotas que ha producido nuestra infortunada estirpe" (tomado de López Portillo, Méndez Reyes y Muñoz Mata, 2004: 105). Para rematar: "Juan Vicente Gómez es un cerdo humano que deshonra nuestra raza y deshonra a la humanidad» (tomado de Krauze, 2005). Durante esa década de distanciamiento formal, otros incidentes de naturaleza 
venía escalando desde su origen y terminó por involucrar a Colombia por los reclamos que algunos estudiantes hicieron a su representación en México a fin de que este país concediera asilo a los perseguidos de la dictadura venezolana (Palacios, 2011: 199-201).

En varios países hispanoamericanos (Colombia, Perú, Chile, Panamá, Costa Rica, Ecuador, Cuba), los estudiantes intentaron aprovechar el considerable prestigio que en todo el continente tenía Vasconcelos para derribar estructuras universitarias arcaicas y petrificadas y para tratar de establecer vínculos estrechos entre las reivindicaciones estudiantiles y las obreras (Fell, 2021: 818).

El episodio peruano también tiene su historia y una figura clave en Haya de la Torre. Al final de su propio exilio, Augusto Leguía, representante de un gobierno modernizador con una progresiva vocación autoritaria (Moraga Valle, 2021: 4), había encontrado en Haya un destacado aliado universitario, pues había protagonizado el movimiento de reforma de San Marcos en favor de la universidad popular, que había tenido una notable participación en las luchas obreras (jornada de ocho horas). Este sería, sin embargo, solo un encuentro coyuntural para ambos. El popular líder trujillista de estudiantes y obreros siguió impulsando los movimientos sociales vinculantes entre el mundo universitario y el del trabajo hasta que el gobierno decidió su detención y exilio en 1923 (Fell, 2021: 830831). De manera paradójica, la reforma universitaria que supuso autonomía, cogobierno y extensión se mantuvo en pie y fue capitalizada solo por Leguía (Marsiske, 2003: 35-43). Se configuraría entonces una crisis que escalaría las cancillerías de México y Perú tras las expresiones públicas de Vasconcelos, por un lado, en contra de una reforma constitucional promovida por Leguía con propósitos de permanencia en el poder y, por otro lado, en defensa del movimiento universitario peruano, ${ }^{9}$ de su inconfundible líder Haya de la Torre y del asilo que a este se le había otorgado en México bajo su cuidado en la Universidad:

En Lima repercutió el movimiento, al cual contesté con una carta abierta en que a pesar mío tuve que atacar a Leguía. Protestó el ministro peruano en la capital de México, pero mi correspondencia con los peruanos circuló por todo el continente. Unas semanas después era expulsado de Lima, Haya de la Torre, el futuro jefe del aprismo que, al llegar a Panamá, me pidió el asilo de México (Vasconcelos, 1979 [1938]: 93). ${ }^{10}$

Un coro de intelectuales se haría eco de la misma acusación política: José Ingenieros, José María Vargas Vila, Rufino Blanco Fombona, Jacinto López, Ri-

conspirativa de asilados venezolanos terminaron relacionando a México con otras acusaciones y señalamientos, hasta que en julio de 1933 tuvo lugar el restablecimiento.

9. Con el que había entrado en contacto en San Marcos en 1916 (Fell, 2021: 795), así como en el marco del Primer Congreso Internacional de Estudiantes celebrado en la ciudad de México (1921), un hito en la historia del movimiento estudiantil americano y ocasión que facilitaría el tejido de redes transnacionales de una generación protagonista en el futuro inmediato. En su marco, la delegación estudiantil mexicana expondría su rechazo temprano al presidente Leguía (Moraga Valle, 2014: 177).

10. El exilio aprista en México tiene un lugar muy especial en la obra del historiador peruano Ricardo Melgar Bao, autor de estudios indispensables como son los publicados en 1992, 2002 y 2018. 
cardo Rojas y Alfredo Palacios; y también lo hicieron diversas confederaciones estudiantiles latinoamericanas. ${ }^{11}$ Una corriente de estudiantes y jóvenes políticos peruanos pudieron acogerse en la representación diplomática mexicana en Lima - anterior a su degradación a archivo itinerante - y eventualmente en México, como el propio Haya de la Torre..$^{12}$ Los estudiantes de la Universidad de Trujillo le habían otorgado a su intercesor Vasconcelos el título de maestro de la juventud. ${ }^{13}$ Vasconcelos afirmaría: «El Perú es mi patria, y por lo mismo no puedo ni ofenderla ni dejar de interesarme por sus asuntos» (Fell, 2021: 835).

En cuestión de un año, en el cual llevó a cabo algunas tareas más bien relajadas cerca de Vasconcelos como "conferencista de historia iberoamericana", «maestro misionero» y miembro del comité de redacción de El Maestro (Fell, 2021: 801), Haya de la Torre pudo ponerse en contacto con los movimientos estudiantil y obrero mexicanos, en particular con Luis N. Morones, líder de la confederación obrera más importante en ese tiempo: la Confederación Regional Obrera Mexicana (CROM). Sin embargo, el proceder cuestionable y sospechoso del cromista en la muerte del senador Francisco Field Jurado inquietó profundamente al joven asilado (Vasconcelos, 1979 [1938]: 180-181). Una idea precisa de sus demás relaciones intelectuales y políticas la da Rubén Ruiz Guerra, que señala a los siguientes: Diego Rivera, José Clemente Orozco, Fermín Revueltas, Carlos Pellicer, José Gorostiza, Jaime Torres Bodet y Moisés Sáenz, además de su notable anfitrión Vasconcelos (Ruiz Guerra, 2007: 125) y el futuro opositor demócrata, y conservador destacado, que sería Manuel Gómez Morín (Melgar Bao, 2018: 19). Antes de poner fin a su breve asilo, Haya de la Torre procedió a la catalización de su temprana experiencia revolucionaria al perfilar su alianza continental antiimperialista, un proyecto colectivo transnacional (Iglesias, 2014: 2) que terminaría de cuajar ya lejos de México, especialmente durante su travesía europea y en su paso por Moscú, con motivo del V Congreso de la Internacional Comunista, y Londres (Jeifets y Jeifets, 2013). Su programa político desarrollaría los siguientes puntos básicos: antiimperialismo estadounidense, unidad latinoamericana, nacionalización progresiva de tierra e industria, internacionalización del canal de Panamá y solidaridad de los pueblos y clases oprimidos (Marsiske, 2003: 44). En compañía de otros 30 estudiantes peruanos en el exilio, Haya entregaría la bandera indoamericana al presidente de la Federación de Estudiantes de México en un acto simbólico realizado el 7 de mayo de $1924 .{ }^{14}$

Vasconcelos y Haya realizaron un viaje juntos a la Universidad de Texas en Austin en junio de 1924, donde finalmente se despidieron después de comer jaibas frescas asadas acompañadas de un vino francés de contrabando. El joven

11. Véase: «Manifiestos que muestran su rechazo al gobierno del presidente Leguía», Guayaquil, 1 de mayo de 1924, en Archivo del Ministerio de Relaciones Exteriores de Perú (en adelante AMRE). Archivo Particular Augusto B. Leguía (APABL). PE/MRREE/AC/ACLEGUIA/0219.

12. Archivo Histórico Genaro Estrada de la Secretaría de Relaciones Exteriores, Ciudad de México ( en adelante AHGE-SRE). Exp. 41-8-8 (II).

13. Paradójicamente, concedido también a Leguía en 1919 (Fell, 2021: 828, 830).

14. Sitio web del Instituto Víctor Raúl Haya de la Torre: www.hayadelatorre.com (consulta: 15 de septiembre de 2020); véase también: Pakkasvirta $(2001: 12,26)$. 
peruano partió a Londres tras su primer exilio en México ${ }^{15}$ «pensionado por los metodistas yankees» y un tanto «disgustado del cafrerismo súbitamente desarrollado en México» (Vasconcelos, 1979 [1938]: 200). ${ }^{16}$ Pero de ningún modo se olvidaría de la añorada aproximación que haría de la revolución mexicana con su país:

Porfirio Díaz[,] como su imitador Leguía en el Perú, entregó México a las garras económicas yanquis para asegurarse él en la tiranía. Porfirio Díaz llevó a México el mismo sistema que Leguía desarrolla: pavimentar calles, exaltar la patriotería, hacer fiestas, enriquecerse y enriquecer una casta y pronunciar discursos hablando del progreso del país... pero la revolución mexicana vino y restableció los derechos del pueblo engañado y oprimido, salvó al país del coloniaje yanqui y estableció el gran sistema social y político que hoy vemos. ${ }^{17}$

\section{La APRA, Leticia y la SDN}

Lo que quedó en México fue un problema sin resolver con mínimas implicaciones para una relación no tan relevante hasta ese momento. $Y$ aunque no hubo ruptura, este tipo de actos siguió alimentando el resentimiento y la sospecha entre las autoridades peruanas. En lo general, la consolidación del régimen posrevolucionario mexicano observaría un empuje invariable al final de la década de 1920 y muy pronto tendría lugar su reinserción en el sistema internacional de entreguerras no solo con la resolución de conflictos significativos con las potencias de la época, sino también con su definición respecto a una colaboración permanente con los nuevos organismos multilaterales representativos de la Ginebra internacional anterior a la segunda guerra mundial. Esto ocurriría en septiembre de 1931, con el ingreso de México en la SDN y la aceptación implícita de nuevas responsabilidades como miembro de una comunidad diversa y formal, de trato recurrente y de búsqueda de acuerdos colectivos ante los problemas ocasionados por los duros reveses económicos y geopolíticos del período. Como miembros de la SDN, tanto México como Perú asumirían compromisos de convivencia y trato bien precisados en su Pacto, reconociéndola como una figura coordinadora de los esfuerzos multilaterales para la resolución de los problemas

15. Vivió otra más entre diciembre de 1927 y mayo de 1928, ya no tan vinculado al gobierno mexicano y en la que, siguiendo a Melgar Bao, «logró la conformación de la célula aprista en México y el controvertido lanzamiento del Partido Nacionalista Libertador del Perú, fuera de dos paralelas y sonadas polémicas sostenidas con José Carlos Mariátegui y Julio Antonio Mella en torno al carácter y proyección ideopolítica de la APRA en el Perú e Indoamérica» (Melgar Bao, 2018: 35-36). Tales polémicas protagonizadas por Haya, junto con la conformación del aprismo como partido, escindieron el movimiento y aproximaron a parte importante al comunismo tras la publicación de los Siete ensayos de interpretación de la realidad peruana en 1928 (Aricó, 1978: XXXI).

16. Las cursivas son mías para destacar tan extraño término, el cual pudo explicarme Gilberto Urbina, especialista en la historia de la ciudad de México. La palabra hace referencia al ambiente caótico que entonces se vivía en esa ciudad capital, haciendo alusión a la Cafrería Británica de la Sudáfrica del siglo XIX, cuyos pobladores nativos eran llamados cafres.

17. Tomado de un reportaje concedido por Haya de la Torre a Edward Read, de la Federated Press de Chicago en Liverpool el 11 de septiembre de 1925, en AMRE-APABL. PE/MRREE/AC/ ACLEGUIA/0117. 
que afectasen la paz internacional; y muy pronto ambos se verían envueltos en dinámicas de este tipo con implicaciones significativas en su relación bilateral.

En el caso particular de México, el problema relacionado con su exclusión temprana de la SDN (París, 1919) y la labor inmediata y sostenida de Venustiano Carranza en su contra definieron una década de ambiguo interés y malentendidos que inesperadamente comprendieron la Organización Internacional del Trabajo pese al interés de México en ella (Herrera León, 2011 y 2020). A la negociación directa entre México y la Secretaría General de la SDN que hizo posible la adhesión mexicana siguió un sorpresivo anuncio de retiro (diciembre de 1932) motivado por el tratamiento societario de la cuestión de Manchuria (Herrera León, 2014: 142-157). Su cumplimiento, sin embargo, quedó sin efecto como resultado del involucramiento de México como comisionado del Consejo de la SDN en los conflictos latinoamericanos del Chaco y Leticia. El último de estos enfrentaría a Colombia y Perú por una zona cauchera en torno al puerto amazónico de Leticia que había sido objeto de una sorpresiva insurrección local peruana con fines reivindicatorios. El conflicto solo llegaría a su fin tras el azaroso retiro, en junio de 1934, de una Comisión internacional dispuesta por la SDN durante un año para la administración del puerto antes de su devolución a Colombia en tanto se negociaba un acuerdo de pacificación y se procedía a un intercambio de ratificaciones que no concluyó hasta septiembre de $1935 .{ }^{18}$

Perú había seguido una trayectoria igualmente accidentada como miembro de la SDN, a la que había acudido tempranamente solicitando la revisión de los acuerdos de paz con Chile y la intervención societaria para la modificación de su frontera Sur. ${ }^{19}$ No consiguió nada ante la firme oposición chilena a una acción plebiscitaria que pasara por encima del artículo 21 del Pacto de la Sociedad, con lo que se garantizaba, según lo previsto en ese artículo, ${ }^{20}$ la validez de la doctrina Monroe como una inteligencia continental americana; esta última, una cuestión aún más polémica por entonces en Ginebra que la relacionada con la cuestión de Tacna y Arica (Perkins, 1963: 327; Gregory, 1921: 241).21

El Oncenio llegaría a su fin del mismo modo en que se había iniciado: con un golpe de Estado. Este se anunciaría en términos explícitamente fascistas como una marcha sobre $\operatorname{Lima}^{22}$ y lo protagonizarían tropas del ejército bajo el

18. Véase la nota 41, también de Herrera León (2009: 185-188; 2014: 217-220). Esta comisión internacional constituyó un episodio excepcional americano en el despliegue internacional de mandatos a cargo de la Sociedad de Naciones en el período de entreguerras. Véase: Pedersen (2015).

19. Bolivia también tomó parte en esta polémica por las provincias de Tacna y Arica (1920-1921), que fue una de las primeras en plantearse tan pronto abrió sus puertas la Sociedad de Naciones. La cuestión del Pacífico en Ginebra, canalizada así por el propio presidente Woodrow Wilson desde la Conferencia de Paz de París (1919) es estudiada en Wehrli (2016: 142-148, 152-154).

20. Artículo 21 del Pacto de la Sociedad de Naciones: «Los compromisos internacionales, tales como los tratados de arbitraje, y las inteligencias regionales, tales como la doctrina Monroe, que aseguran el mantenimiento de la paz, no se consideran incompatibles con ninguna de las disposiciones del presente Pacto».

21. A propósito de esta cuestión, más política que jurídica, véase: Wehrli (2016: 355-406).

22. Consúltense los expedientes de cables dirigidos al Estado Mayor peruano en: AMRE-APABL. PE/MRREE/AC/ACLEGUIA/0218. 
mando del teniente coronel Luis Miguel Sánchez Cerro. ${ }^{23}$ El cuartelazo en cuestión inauguraría una nueva etapa de militarismo en Perú, ${ }^{24}$ caracterizada por una cruenta lucha contra el aprismo y el también prohibido Partido Comunista Peruano $(\mathrm{PCP}) .{ }^{25}$

Fue significativo que tres gobiernos (Leguía, Sánchez Cerro y Benavides) mandasen a la clandestinidad y/o destierro a sus líderes y militantes, también a las cárceles y a la muerte, siguiendo un periplo parecido a la accidentada vida política de los comunistas (Melgar Bao, 2018: 24).

Entonces tendría también lugar el conflicto con Colombia por el puerto y corredor geográfico de Leticia que en 1930 había intercambiado Perú por otros territorios próximos a Ecuador mediante el Tratado secreto Salomón-Lozano (1922); todo esto en el marco de un proceso de definición de fronteras con el que Perú, por lo que respecta a la Amazonía, se desentendía de una zona remota y de difícil acceso que se caracterizaba por revueltas y rebeliones interdepartamentales contra el gobierno central. ${ }^{26}$

Haya de la Torre registraría al aprismo como contendiente de Sánchez Cerro en las elecciones presidenciales convocadas después del golpe y de las que el mando militar de Arequipa saldría triunfante y dispuesto a asediar al aprismo pese a su popularización entre estudiantes, intelectuales y activos de la Marina de Guerra del Perú. El enfrentamiento fue escalando a partir de 1932 -el año que Guillermo Thorndike acuñó como «de la barbarie» - con el amotinamiento en los cruceros Grau y Bolognesi y la toma orquestada por la APRA del cuartel O'Donovan en Trujillo, cuyo respectivo desenlace fue el fusilamiento de los insurrectos en las ruinas de Chan Chan. ${ }^{27}$ La prensa continental se haría eco de las palabras de Vasconcelos ante la tragedia:

23. El golpe de Estado fue objeto de seguimiento por parte de la representación diplomática mexicana en Lima y se conserva en: AHGE-SRE, exp. III-1315-4.

24. Entendiendo por este un período de enorme influencia castrense, desbordante de la esfera del gobierno central y acogido socialmente como una medida de resguardo ante el riesgo de la lucha revolucionaria social pronosticada por Mariátegui y esperada por Haya y el aprismo en general. Esta etapa de militarismo con un sombrío ascendente aspiracional fascista comprendió el gobierno inmediato del general Óscar R. Benavides (1933-1939), principal defensor de Leticia años antes. Jorge Basadre Grohmann precisó muy bien lo anterior en su monumental Historia de la República del Perú, que cuenta con muchas ediciones a partir de 1939 y ampliaciones que hacia 1968 comprendieron el período de irrupción de las masas en la política después del Oncenio de Leguía. Véase una recreación reciente de contexto en: Sandoval López (2020: 89-90).

25. El testimonio de la legación mexicana en Lima, en: AHGE-SRE, exp. 34-4-52. Véanse también: Manrique (2009: 97-102) y, en especial, Rénique (2007: 467-472).

26. Leguía había sido el impulsor de estas insoslayables definiciones territoriales que, frente a Colombia, supusieron igualmente la obtención de territorios sobre el Alto Putumayo y otros más próximos a la frontera con Ecuador mediante el referido Tratado secreto. En 1930, ocho años después de su firma, concluyó formalmente el intercambio de poblaciones y territorios entre ambos países. Al respecto pueden verse: Arana (1965, I: 63-64) y St. John (1976: 331-335). A propósito de los antecedentes de revuelta y rebelión de esta zona prácticamente ajena al poder central, véase el interesante informe militar del teniente Emilio D. Vizcarra S. en su campaña de pacificación de Loreto, fechado en Lima el 17 de mayo de 1922: AMRE-APABL. PE/MRREE/AC/ACLEGUIA/0127.

27. Véase la nota 23. 
Las matanzas siempre han sido ocasionadas por la soldadesca embrutecida por el alcohol y la coca, o por criminales asalariados; pero estos últimos muertos son la obra de dignos oficiales, que[,] cerrando los ojos para no ver la tragedia y el dolor del pueblo peruano, muy serenamente han cumplido la consigna de los amos que saben pagar bien. ${ }^{28}$

En este contexto, el surgimiento inesperado, el 1 de septiembre, de actividad armada en la frontera con Colombia en torno a Leticia llevó a pensar en la posible extensión de la lucha aprista a aquella zona y a una labor de sabotaje planeada para ocasionar un conflicto fronterizo. Se trataría en realidad de una acción con propósitos de reivindicación organizada por los caucheros y hacendados peruanos de Loreto, cuya actividad de explotación resentía ya las modificaciones geográficas y administrativas dispuestas por el Tratado Salomón-Lozano. No obstante, la APRA sería inmediatamente señalada por el gobierno de Sánchez Cerro como responsable de estos actos, lo cual fue igualmente informado a Colombia en un primer momento. Solo cuando se tuvo conocimiento de la verdadera naturaleza de la revuelta, Sánchez Cerro decidió respaldarla. El giro de este gobierno militarista en favor de los rebeldes locales fue a todas luces precipitado y oportunista con propósitos de legitimación ante las inquietas masas populares y militares del país; ${ }^{29}$ un oportuno distractor y halo de renovación cuyas bondades serían igualmente apreciadas por el asediado gobierno liberal de Enrique Olaya Herrera en Colombia.

En cuanto a las relaciones entre México y Perú, estas habían superado la década de 1920 entre encargados de negocios y enviados extraordinarios para la ocasión de fiestas nacionales o investiduras presidenciales (Montalvo, 1981: 50-53). La relación seguía resintiendo las expresiones y gestos antiautoritarios por parte de México, así como el juicio de rechazo al anticlericalismo y la persecución de opositores políticos agradables a la revolución por parte de Perú. ${ }^{30}$ La situación en general pudo cambiar a principios de 1931 cuando el nuevo gobierno de Pascual Ortiz Rubio (antiguo embajador en Alemania y Brasil) y su cancillería, a cargo de Genaro Estrada, se interesaron por elevar las legaciones de ambos países al nivel de embajada ${ }^{31}$ e incluso felicitaron oficialmente a Sánchez Cerro en su toma de posesión (Montalvo, 1981: 58). No obstante, el aparente desencanto del gobierno peruano por el régimen que estimaba el principal benefactor internacional de la APRA lo confirmaría una nueva crisis bilateral suscitada por la prensa limeña en febrero de 1932. El Comercio publicaría una polémica carta escrita por Haya de la Torre en Berlín pocos años antes (septiem-

28. José Vasconcelos, "Malditos sean quienes hacen sufrir al Perú». El Diario, La Paz, 15 de mayo de 1932, en AHGE-SRE, exp. III-1313-10 (II). (2016)

29. Un trabajo de investigación reciente y bien logrado sobre este conflicto es el de Arango

30. Rubén Ruiz Guerra encuentra muy sugerente el ámbito oficioso de relación entre grupos católicos y de ideología conservadora entre México y Perú: «Si los lazos económicos y comerciales entre México y Perú eran ciertamente escasos, y los vínculos intelectuales estaban muy localizados, en materia religiosa parece haber existido mayor intercambio entre ambos países" (Ruiz Guerra, 2007: 144).

31. No supone ninguna diferencia el hecho de que no tuviera suerte en ello. 
bre de 1929) en la que se precisaba el uso de la valija diplomática mexicana - cuando la clandestinidad epistolar representó prácticamente todo para el aprismo (Iglesias, 2014: 3) - para seguir en contacto con el célebre comunista peruano José Carlos Mariátegui.

La publicación de la misiva, vista a partir de las condiciones internas del Perú, fue magnificada al promulgarse la Ley de Seguridad Interior que ilegalizó al Partido Aprista Peruano y buscó desarticular los canales externos que lo alimentaban. A su vez, la carta dio cuenta de la organización emprendida desde el exilio para integrar un «ejército sobre la base de 2.500 hombres de Talara» que derrocara al entonces presidente Leguía mediante la vía armada y con el apoyo de un movimiento político electoral impulsado desde territorio andino (Andújar de Jesús, 2006: 118).

La intención de Ortiz Rubio y Estrada por hacer sanar las relaciones con Perú, y acaso potenciarlas, solo tuvo una existencia efímera. Vinieron enseguida los consabidos actos formales de desprecio mutuo y degradación, increíblemente posible, de representaciones; todo esto en mayo de 1932, tras la detención de Haya de la Torre en un domicilio vecino y supuestamente comunicado por «una trampa»32 con la legación mexicana en Perú e involucrando a sus diplomáticos responsables y al célebre indigenista Moisés Sáenz (Melgar Bao, 2018: 38-40; Montalvo, 1981: 59-64). El canciller Manuel C. Téllez lo expresaba así:

No existe constancia alguna en esta Secretaría, respecto al hecho de que se haya permitido al señor Haya de la Torre hacer uso de las valijas diplomáticas mexicanas para el envío de correspondencia de México a Lima [...]. En vista de lo injustificado, insólito y sin precedentes del pedimento de retiro de todo el personal de la legación de México en Lima, hecho por la cancillería del gobierno del coronel Sánchez Cerro, el gobierno de México no puede menos que ver en él el propósito de interrumpir el trato que mantienen los dos Estados y[,] en consecuencia, inmediatamente giré instrucciones por la vía telegráfica al personal de nuestra legación en Lima de trasladarse a Panamá, y hoy he entregado sus pasaportes al señor ministro del Perú, don Óscar Barrenechea y Raygada, y al personal de la legación peruana en esta capital. ${ }^{33}$

Sería precisamente en este momento cuando México se vería involucrado en los intentos societarios de resolución diplomática del conflicto de Leticia. En su calidad de miembro del Consejo integraría, ${ }^{34}$ junto con España e Irlanda, una Comisión especial de tres miembros para la atención de este y de la guerra del Chaco, la cual se desarrollaría paralelamente entre 1932 y $1935 .{ }^{35} \mathrm{Al}$ margen también de la relación política bilateral, México y Perú se verían relacionados de forma extraordinaria e indirecta por un proyecto internacional para la aprecia-

32. Así lo reprodujo ampliamente la prensa peruana según el informe del agregado militar a la legación de México en Perú, el teniente coronel Antonio Grimaldi. Panamá, 23 de mayo de 1932, AHGE-SRE, exp. III-1313-10 (II).

33. AHGE-SRE, exp. III-1313-10 (I).

34. Tomando el lugar que dejaría Guatemala al cumplirse su período como consejero.

35. El conflicto del Chaco involucraría a Bolivia y Paraguay como consecuencia de una añeja indefinición limítrofe a lo largo de este inhóspito, aunque potencialmente rico, territorio desértico. Véase: Herrera León (2009). 
ción del precio de la plata, el cual representaba para México una medida importante para amortiguar la crisis internacional y afianzar un proyecto de naturaleza bimetalista impulsado por la figura del expresidente Plutarco E. Calles. Todo dependería, sin embargo, de un acuerdo de explotación limitada y venta moderada de este metal entre sus principales productores y tenedores mundiales, México y Perú entre los principales (Herrera León, 2010).

El peso de la imagen revolucionaria mexicana iba encontrando considerables contrapesos conforme el país buscaba una mejor adaptación en el mundo, y el distanciamiento por los motivos referidos con Perú perdía su lógica. Un estado de suspensión de relaciones en un sistema de interrelación compleja que tenía sobre la mesa delicados problemas políticos y económicos por resolver no podía sino mirar con preocupación este tipo de desventajas. ${ }^{36}$ El distanciamiento debía llegar a su fin y la diplomacia republicana española, representativa del único par internacional de México en esos años, contribuiría a este pertinente y necesario reencuentro (Ojeda Revah, 2004: 70). ${ }^{37}$

La labor de la diplomacia española, preferida con relación a la argentina, se inició a mediados de junio de 1932 y facilitó las negociaciones en Madrid entre México y Perú. ${ }^{38}$ El restablecimiento de relaciones se complicaría como consecuencia de las exigencias de ambas partes y la negociación llegaría a un aparente punto muerto en septiembre. Permaneció así hasta mayo de 1933, una vez se instruyó a Genaro Estrada, a la sazón embajador en Madrid, acerca de que «en ocasión de las primeras Conferencias de Londres y la Panamericana [de Montevideo de 1933], México desea demostrar sus propósitos de cooperación» (Montalvo, 1981: 69). El excanciller replanteó entonces el tema de la mediación española con Perú para llegar a un acuerdo definitivo de restablecimiento. La exaltación revolucionaria, tanto de parte de México como de Perú, fue percibida como obstinación en esta segunda etapa de negociación. En palabras del experimentado ministro peruano Óscar Barrenechea y Raygada, «había la absoluta certeza de que mientras el presidente Sánchez Cerro rigiera los destinos del Perú, México no haría de su parte ninguna gestión encaminada a restablecer sus relaciones diplomáticas con nuestro país». ${ }^{39}$ La muerte trágica del presidente peruano a manos de un joven aprista después de pasar revista a sus tropas movilizadas contra Colombia contribuyó a despejar por partida doble el

36. Así lo sugiere el seguimiento minucioso del desencuentro peruano-mexicano que haría la diplomacia británica al servicio de la principal potencia ginebrina, anfitriona además de la Conferencia Monetaria y Económica Mundial (Londres, 1933). Resulta muy provechosa toda la documentación reunida por el Foreign Office al respecto de una diferencia binacional con implicaciones evidentemente multilaterales. Enseguida me referiré a las Archivos Nacionales del Reino Unido en Kew (en adelante, ANRU), así como a la serie de expedientes bajo el título genérico «Peruvian relations with Mexico» en los fondos documentales del Foreign Office bajo los números correspondientes a las cajas del acervo 177 y 371 .

37. Véanse también: Jorge (2016) y Sánchez Andrés y Pérez Herrero (2015).

38. Genaro Estrada tomó parte en estas negociaciones en calidad de embajador de México en Madrid, representación de la que se hizo cargo tras el final precipitado del gobierno de Ortiz Rubio y de su consecuente salida de la cancillería.

39. «Recordando un incidente internacional con el Perú en 1932», Lima, en ANRU. FO 177. Caja 492. Exp. 130. 
ambiente cerrado tanto en esta mesa como en la dispuesta en Ginebra para resolver el conflicto amazónico de Leticia. Su sucesor, también militar, el general Óscar R. Benavides, procuró zanjar el conflicto facilitando la intervención de Ginebra y un entendimiento con Colombia, lo cual contuvo por algún tiempo la polarización y enfrentamiento internos en Perú bajo la proclama «paz y concordia» (Melgar Bao, 2018: 42; Skidmore y Smith, 1996: 229). El 21 de mayo de 1933 se reanudaron las relaciones entre México y Perú por intermediación del ministro de Estado español Luis de Zulueta con base en el interés manifiesto y renovado de las partes. ${ }^{40}$

La colocación del problema de restablecimiento de relaciones con Perú en la agenda bilateral y multilateral hispano-mexicana supuso, pues, uno de los puntos más altos al que pudo ser llevado un tema coyunturalmente relevante y determinante tanto del buen curso de las negociaciones de paz con relación a Leticia que estuvieron a cargo del presidente de la Comisión de Tres, el mexicano Francisco Castillo Nájera, ${ }^{41}$ como del acuerdo privado de apreciación de la plata firmado en Londres en 1933, y del que México fue coartífice y un importante impulsor. Este hecho antecedió por casi tres meses a la liberación, ya nunca más vinculable a la relación bilateral, del líder fundador del aprismo Víctor Raúl Haya de la Torre.

\section{A modo de conclusión}

Nada cambió notablemente en la relación entre México y Perú que explicara de manera lógica su circunstancial reanudación; ${ }^{42}$ sencillamente hubo un reacomodo de prioridades impuesto por la incursión de México en otros planos de actividad internacional y la búsqueda en ellos de acuerdos políticos y económicos de naturaleza colectiva. El desenvolvimiento del México posrevolucionario en un ámbito multilateral complejo desde su ingreso en la SDN introdujo cambios significativos en su proyección y conducta internacionales que sin duda relativizaron la actitud suspicaz y defensiva implícita en los lances contra los déspotas regionales que ilustraron las primeras páginas de este artículo. Esta superposición de planos internacionales supuso nuevas interconexiones sensibles y exi-

40. AHGE-SRE, exps. III-108-27 y III-1313-10 (II).

41. Estas condujeron a la firma de un acuerdo en el marco del LXXIII Consejo de la Sociedad de Naciones el 25 de mayo de 1933. La SDN se hizo cargo de Leticia durante un año a partir del arribo al puerto de una comisión internacional creada con este propósito tras su devolución el 23 de junio de 1934. El riesgo de una reanudación de hostilidades permaneció latente hasta el intercambio de ratificaciones de un detallado acuerdo de pacificación firmado en Río de Janeiro el 24 de mayo de 1934. Por tanto, el Comité Consultivo de la Sociedad de Naciones, aún bajo la presidencia del mexicano Castillo Nájera, no dejó de actuar internacionalmente - en especial ante Colombia - hasta el intercambio de ratificaciones, en septiembre de 1935. Entonces se puso punto final al conflicto amazónico. Véase: Herrera León (2009: 191-195). Las negociaciones colombo-peruanas a cargo de Afranio de Mello Franco en Río de Janeiro fueron seguidas por Reyes (2010: 275-313).

42. El curso de la relación no observó cambios cualitativos no obstante la elevación del rango de sus representaciones a embajadas entre 1936 y 1937. Véase: Andújar de Jesús (2006). 
gió una mejor articulación entre política y diplomacia, dejando muy poco espacio y sustrayendo legitimidad a las manifestaciones de actores oficiosos como ese incontenible Vasconcelos. Esta sutil calibración e importante replanteamiento de la política exterior mexicana en la década de 1930 es la que ha buscado enfatizar este artículo a través del análisis de la accidentada relación con Perú. Si bien la ruptura de relaciones con este país puede hablar de la ausencia de una política exterior impermeable a vaivenes imprevistos, con una vocación estabilizadora y cuadros capaces de representarla, la reanudación de las relaciones podría representar muy bien ese cambio cualitativo por los aspectos que incidieron en ello; en otras palabras, la instrumentación lógica y profesional de una política exterior mejor articulada respecto de los intereses nacionales en diversos planos de interacción.

La casi total salida de escena de los intelectuales, al menos de esta políticodiplomática, tiene que ver no solo con una profesionalización del servicio exterior, sino también con el desarrollo amplio de áreas más pertinentes para su actividad, como la cultural, la educativa, la editorial o la periodística. Ocasionalmente se les ve asumir la titularidad de algunas representaciones que armonizan con su figura, pero esto suele responder en parte a motivos de prestigio y tradición que se hacen eco de su importante presencia en el pasado de la política exterior mexicana. Sin embargo, se suele echar de menos su espíritu libre y resuelto cuando es necesario hacerse escuchar con un sentido de justicia y moralidad universales.

\section{Bibliografía}

Altamirano, Carlos (2008). «Introducción general». En: AltamiRano, Carlos (dir.). Historia de los intelectuales en América Latina. Buenos Aires: Katz Editores, págs. 9-27.

ANDÚJAR DE JESÚS, Eusebio (2006). «Aspiraciones antiimperialistas e intereses nacionales: las relaciones exteriores entre México y Perú (1930-1945)». Latinoamérica, Ciudad de México, 43, págs. 113-132.

Araujo Arana, Humberto (1965). Conflicto fronterizo Perú-Colombia, 1932-1933. Tomo I. Lima: Huascarán.

ARIcó, José (1978). Mariátegui y los orígenes del marxismo latinoamericano. México: Siglo XXI.

Camacho Arango, Carlos (2016). El conflicto de Leticia (1932-1933) y los ejércitos de Perú y Colombia. Bogotá: Universidad Externado de Colombia.

Dumont, Juliette (2018). Diplomaties culturelles et fabrique des identités. Argentine, Brésil, Chili (1919-1946). Rennes: Presses Universitaires de Rennes.

EstradA, Genaro (1923). Las relaciones entre México y Perú. La misión de Corpancho. México: Secretaría de Relaciones Exteriores.

FeLL, Claude (2021). José Vasconcelos. Los años del águila, 1920-1925. Educación, cultura e iberoamericanismo en el México posrevolucionario. Tomo II. México: Universidad Nacional Autónoma de México.

GREGORY, Charles Noble (1921). «The first assembly of the League of Nations». The American Journal of International Law, Washington D.C., 2, págs. 240-252. 
Guzmán y Raz Guzmán, Jesús (1925). Las relaciones diplomáticas de México con SudAmérica. México: Secretaría de Relaciones Exteriores.

HerRera León, Fabián (2009). La política mexicana en la Sociedad de Naciones ante la guerra del Chaco y el conflicto de Leticia, 1932-1935. México: Dirección General del Acervo Histórico Diplomático de la Secretaría de Relaciones Exteriores.

HeRRERA León, Fabián (2010). «México en la Conferencia Económica Mundial de Londres: el Acuerdo de la Plata de 1933». América Latina en la Historia Económica: Revista de Investigación, Ciudad de México, 34, págs. 209-234.

HERRERA LEÓN, Fabián (2011). «México y la Organización Internacional del Trabajo: los orígenes de una relación, 1919-1931». Foro Internacional, Ciudad de México, 204, págs. 336-355.

Herrera León, Fabián (2014). México en la Sociedad de Naciones, 1931-1940. Ciudad de México: Dirección General del Acervo Histórico Diplomático.

HerRera LeÓn, Fabián (2020). «México y la Sociedad de Naciones: sobre su exclusión e ingreso (1919-1931)». Historia Mexicana, Ciudad de México, 276, págs. 1647-1680.

IGLESIAS, Daniel (2014). Les mythes fondateurs du Parti Apriste Péruvien. París: Éditions de I'IHEAL.

JeIfETS, Lazar y JeIfETS, Víctor (2013). «Haya de la Torre, la Comintern y el Perú: acercamientos y desencuentros». Pacarina del Sur, Ciudad de México, 16, [en línea].

JORGE, David (2016). Inseguridad colectiva. La Sociedad de Naciones, la guerra de España y el fin de la paz mundial. Valencia: Tirant Humanidades.

JUDT, Tony (2008). Sobre el olvidado siglo XX. Madrid: Taurus.

KRAUZE, Enrique (1996 [1976]). Caudillos culturales en la revolución mexicana. Ciudad de México: Siglo XXI Editores.

Krauze, Enrique (2005). "México y Venezuela: crisis de ayer y hoy». Reforma, Ciudad de México, 20 de noviembre de 2005. Disponible en: www.enriquekrauze.com.mx/ mexico-venezuela-crisis-ayer-hoy/ (consulta: 24 de mayo de 2021).

LóPEZ-PoRtillo T., Felícitas; MÉndez ReYES, Salvador y MuÑoz MATA, Laura (2004). Bajo el manto del libertador. Relaciones de México con Colombia, Panamá y Venezuela, 1821-2000. Ciudad de México: Secretaría de Relaciones Exteriores.

MANRIQUE, Nelson (2009). «iUsted fue aprista!». Bases para una historia crítica del APRA, Lima: Consejo Latinoamericano de Ciencias Sociales / Pontificia Universidad Católica del Perú.

MARSISKe, Renate (2003). Movimientos estudiantiles en América Latina: Argentina, Perú, Cuba y México, 1918-1929. Ciudad de México: Universidad Nacional Autónoma de México.

Melgar BAO, Ricardo (1992). «Las lecturas andinas de la revolución mexicana». Cuicuilco, Ciudad de México, 31-32, págs. 59-70.

Melgar BaO, Ricardo (2002). «Redes del exilio aprista en México (1923-1924): una aproximación». En: YANKELEVICH, Pablo (ed.). México, país refugio. La experiencia de los exilios en el siglo Xx. Ciudad de México: Instituto Nacional de Antropología e Historia / Plaza y Valdés, págs. 255-263.

Melgar Bao, Ricardo (2018). Redes e imaginario del exilio en México y América Latina: 1934-1940. México: CIALC-UNAM.

Montalvo, Angélica (1981). Representantes de México en Perú (1821-1981). Ciudad de México: Secretaría de Relaciones Exteriores. 
Moraga Valle, Fabio (2014). «Reforma desde el sur, revolución desde el norte. El primer Congreso Internacional de Estudiantes de 1921». Estudios de Historia Moderna y Contemporánea de México, Ciudad de México, 47, págs. 155-195.

Moraga Valle, Fabio (2021). «El Congreso Iberoamericano de Estudiantes Socialistas de Guadalajara, 1936. Las tensiones ideológicas entre internacionalismo y latinoamericanismo». Revista Izquierdas, Santiago de Chile, 50, págs. 1-21.

OJedA ReVAH, Mario (2004). México y la guerra civil española. Madrid: Turner.

ORWELL, George (2009 [1940]). «El león y el unicornio: el socialismo y el genio de Inglaterra». En: ORWELL, George. El león y el unicornio y otros ensayos. México: Fondo de Cultura Económica / Turner, págs. 97-124.

PAKKASVIRTA, Jussi (2001). «Víctor Raúl Haya de la Torre en Centroamérica. ¿La primera y última fase del aprismo internacional?». Revista de Historia, 44, págs. 9-31.

Palacios, Guillermo (2011). América del Sur. Ciudad de México: Dirección General del Acervo Histórico Diplomático de la Secretaría de Relaciones Exteriores.

PALACIOS, Guillermo (2017). «La recepción de la revolución mexicana en América del Sur». Anuario de Historia de América Latina, Münster, 54, págs. 81-107.

Pedersen, Susan (2015). The guardians. The League of Nations and the crisis of Empire. Nueva York: Oxford University Press.

PERKINS, Dexter (1963). A history of the Monroe Doctrine. Boston: Little, Brown \& Company.

PITA GonzÁLEZ, Alexandra (2014). Educar para la paz: México y la cooperación intelectual internacional, 1922-1948. Ciudad de México: Dirección General del Acervo Histórico Diplomático de la Secretaría de Relaciones Exteriores / Universidad de Colima.

PITA GonZÁLEZ, Alexandra (2016). Redes intelectuales transnacionales en América Latina durante la entreguerra. Ciudad de México: Miguel Ángel Porrúa / Universidad de Colima.

PITA GonzÁlez, Alexandra (2019). «América (Latina) en París: Mistral, Reyes y Torres Bodet en la Colección Iberamericana, 1927-1940». En: HeRRERA León, Fabián y WeHRLI, Yannick (eds.). América Latina y el internacionalismo ginebrino de entreguerras: implicaciones y resonancias. Ciudad de México: Dirección General del Acervo Histórico Diplomático de la Secretaría de Relaciones Exteriores, págs. 241-275.

ReAL de AzúA, Mario Federico (1978). «La misión diplomática del peruano Manuel Corpancho, 1862-1863». Historia Mexicana, Ciudad de México, 1, págs. 62-81.

RÉNIQUE, José Luis (2007). «Una larga marcha andina: tradición radical y organización revolucionaria en el Perú». En: ConcheIRo, Elvira; ModonesI, Massimo y CRESPO, Horacio (eds.). El comunismo: otras miradas desde América Latina. Ciudad de México: Universidad Nacional Autónoma de México, págs. 459-504.

REYES, Alfonso (2010). Relaciones internacionales. Ciudad de México: Fondo de Cultura Económica / Cátedra Alfonso Reyes del Tecnológico de Monterrey.

RIVERA MIR, Sebastián (2018). Militantes radicales de la izquierda latinoamericana en México, 1920-1934. Prácticas políticas, redes y conspiraciones. Ciudad de México: El Colegio de México / Secretaría de Relaciones Exteriores.

ROBINET, Romain (2015). "L'esprit et la race. Le mouvement étudiant face à la Révolution mexicaine (1910-1945)». Tesis de doctorado en Historia. París: Centro de Estudios Históricos de El Colegio de México.

Ruiz GuerRA, Rubén (2007). Más allá de la diplomacia. Relaciones de México con Bolivia, Ecuador y Perú, 1821-1994. Ciudad de México: Dirección General del Acervo Histórico Diplomático de la Secretaría de Relaciones Exteriores. 
SÁnchez Andrés, Agustín y Pérez Herrero, Pedro (2015). Historia de las relaciones entre España y México, 1821-2014. Madrid: Marcial Pons / Instituto de Investigaciones Históricas de la Universidad Michoacana de San Nicolás de Hidalgo / Instituto Universitario de Investigación de Estudios Latinoamericanos de la Universidad de Alcalá de Henares.

SANDOVAL LóPEZ, Pablo Gustavo (2020). «Nombrar al indio. Representaciones y prácticas de la antropología en Perú (1942-1990)». Tesis de doctorado en Historia. Ciudad de México: Centro de Estudios Históricos de El Colegio de México.

Skidmore, Thomas E. y Smith, Peter H. (1996). Historia contemporánea de América Latina. Barcelona: Crítica.

ST. JOHN, Ronald Bruce (1976). «The end of innocence: Peruvian Foreign Policy and the United States, 1919-1942». Journal of Latin American Studies, Cambridge, 2, págs. 325-344.

VAsconcelos, José (1979 [1938]). El desastre. Ciudad de México: Jus.

WEHRLI, Yannick (2016). États latino-américains, organismes multilatéraux et défense de la souveraineté. Entre Société des Nations et espace continental panaméricain (19191939). Tesis de doctorado en Historia. Ginebra: Université de Genève.

YANKELEVICH, Pablo (2003). La revolución mexicana en América Latina: intereses políticos e itinerarios intelectuales. Ciudad de México: Instituto Mora.

ZAPATA, Francisco (2001). Ideología y política en América Latina. Ciudad de México: El Colegio de México.

Fecha de recepción: 19 de octubre de 2020

Fecha de aceptación: 25 de mayo de 2021

Fecha de publicación: 22 de diciembre de 2021 